\title{
CONFLUENCIA DE MODALIDADES DIALOGALES EN LA HONRA DE ESCRIBANOS DE PEDRO DE MADARIAGA
}

\author{
RAFAEL MALPARTIDA TIRADO \\ Universidad de Málaga
}

U uestros escritores renacentistas, ante la página en blanco y con la categorizaciones determinadas. Sus modelos no provenían de la teorización sobre el género, sino de las propias realizaciones desde la literatura grecolatina hasta sus contemporáneos, sin olvidar que la práctica del diálogo se incluía en la formación retórica del estudiante.

Atendiendo a los prólogos de los diálogos, es evidente cuán ajenos permanecían a construcciones tipológicas como las propuestas por los investigadores modernos. Ahora bien, estos intentos categorizadores, a pesar de su carácter postizo, pueden resultar de gran utilidad taxonómica, en especial para los estudios de conjunto sobre este género.

Una distinción matriz que aflora en una de las tardías consignas teóricas sobre el diálogo, por ingenua que parezca, da cuenta de una segura división entre lo que podemos denominar diálogos polémicos y diálogos catequísticos. Se trata del último apartado del Arte de Retórica (1578) de Rodrigo Espinosa de 
Rafael Malpartida Tirado

Santayana, en cuyo «Aviso general de la materia de los diálogos» señala lo siguiente:

[...] conviene, a saber, tener advertencia si las personas que preguntan saben el arte y materia de que se haze la interrogación o no. Si la saben, se introduzirán no como puros y simples interrogadores della, mas introduzirlos argumentando y contendiendo, lo que se haze en los diálogos de Platón y en los Saturnales de Macrobio y en todos los famossos diálogos; si no la saben, devénse introduzir interrogando simplemente, sin contienda ni argumentos, y con una cierta reverencia ${ }^{1}$.

A partir de esta distinción básica, y contando con las aproximaciones tipológicas y las matizaciones de los críticos, se aprecian variables como la mayor o menor apertura en los polémicos²; la tendencia a la disgregación temática y a la estructuración acumulativa ${ }^{3}$, representada por el Jardín de flores curiosas de Antonio de Torquemada, el Diálogo en laude de las mujeres de Juan de Espinosa o los Diálogos de agricultura cristiana de Juan de Pineda; el diálogo como soporte de una narración extensa ${ }^{4}$, ya sea a partir de un dinámico

1 «Institución de los diálogos», en Arte de Retórica, Madrid, Guillermo Drouy, 1578, fol. 80.

2 Jacqueline Ferreras ha considerado cinco tendencias que abarcan progresivamente «del diálogo cerrado al diálogo abierto», dependiendo de la intención del autor (Los diálogos humanísticos del siglo XVI en lengua castellana, Murcia, Universidad, 2003, págs. 627-637, versión española de su trabajo Les dialogues espagnoles du XVIe siécle ou l'expression littéraire d'une nouvelle conscience, París, Didier Érudition, 1985, 2 vols). Al margen de que coincidamos o no con los ejemplos aducidos en cada categoría, su propuesta tipológica es la más completa y sólida con la que contamos por el momento.

3 Cabría considerar, en esos casos, la existencia de un diálogo misceláneo, como Asunción Rallo sugirió respecto al Diálogo en laude de las mujeres de Juan de Espinosa (La prosa didáctica en el siglo XVI, Madrid, Taurus, 1987, pág. 98), y cuyas características distintivas frente a la miscelánea en forma monológica explicó esta misma autora a propósito del Jardín de flores curiosas de Antonio de Torquemada («Las misceláneas: conformación y desarrollo de un género renacentista», en Edad de Oro, III, 1984, págs. 159-180). Es preciso estudiar los rasgos comunes de obras como los Diálogos de filosofía natural y moral de Pedro de Mercado o los Diálogos de agricultura cristiana de Juan de Pineda para que el término rinda taxonómicamente. Lina Rodríguez Cacho considera este último título como el «ejemplo máximo de diálogo misceláneo o enciclopédico de la época» («Los símiles corporales entre el sermón y el coloquio misceláneo. Las Comparaciones de Pérez de Moya», en A. Redondo [ed.], Le corps comme métaphore dans l'Espagne des XVIe et XVIIe siècles. Du corps métaphorique aux métaphores corporelles, París, Publications de la Sorbonne, 1992, pág. 245).

4 A este tipo de diálogo se ha referido específicamente Florencio Sevilla Arroyo en «Diálogo y novela en el Viaje de Turquía», en Revista de Filología española, LXXVII, 1997, págs. 69-87. Para otros ejemplos afines, $c f$. el artículo de Jacqueline Ferreras «Del diálogo humanístico a la novela», en $\mathrm{M}^{\mathrm{a}}$. Carmen Iglesias et al. (eds.), Homenaje a José Antonio Maravall, Madrid, Centro de Investigaciones Sociológicas, 1985, vol. 1, pp. 349-358, y otro trabajo de Sevilla Arroyo, «Los diálogos narrativos: entre novela y coloquio», en Ínsula, 542, 1992, págs. 15-19. Téngase en cuenta, a propósito del marbete diálogo narrativo, que puede llevar a error al coincidir con el que se opone a diálogo 
interrogatorio, como en el Viaje de Turquía, o en busca del consuelo que reporta la comunicación de los pesares, según apreciamos en el séptimo de los Coloquios satíricos de Torquemada; o la explotación de técnicas dramáticas y resortes lucianescos para desmontar las apariencias y realizar crítica social, empresas asumidas por Alfonso de Valdés en su Diálogo de Mercurio y Carón y por Cristóbal de Villalón en El Crótalon ${ }^{5}$.

Son variantes que dan cuenta de la riqueza de un género cuya literariedad ha sido cuestionada a menudo por sus concomitancias con el tratado, a pesar de encontrarse en la encrucijada del ensayo moderno, prefigurándolo con su particular diseño, y por tanto en una línea casi opuesta 6 . En todo caso, el acercamiento más frecuente, que ha hecho olvidar a veces sus características propias, ha sido al contenido idológico de estos textos. Así estaba la cuestión hasta los trabajos de José Lara Garrido sobre los Diálogos de la montería de Luis Barahona de Soto7, Marie-Sol Ortola sobre el Viaje de Turquía8, Leonardo Romero Tobar sobre los Coloquios satíricos de Antonio de Torquemada ${ }^{9}$ A Asunción Rallo sobre el Diálogo de Mercurio y Carón de Alfonso

dramático por la presencia de una instancia narrativa que distribuye los turnos de intervención, por lo que sería recomendable una mayor precisión terminológica.

5 Cf. Asunción Rallo, Erasmo y la prosa renacentista española, Madrid, Laberinto, 2003, págs. 131-156 y 242-256.

${ }^{6}$ Juzgando que «sobre los temas culturales en que no hay tesis establecidas, se trata en forma dialogada», Ciriaco Morón Arroyo consideró en uno de los primeros artículos sobre este género que «el diálogo en el siglo XVI resulta así el precedente del ensayo moderno» («Sobre el diálogo y sus funciones literarias», en Hispanic Review, 41, 1973, pág. 279). En un coherente estudio de conjunto sobre la prosa no novelesca del siglo XVI, donde se incluye el diálogo junto a la miscelánea y la epístola como géneros predilectos y característicos de nuestros humanistas, Asunción Rallo advierte lo siguiente: «quizá equivocando la verdadera naturaleza de esta prosa, durante mucho tiempo se la ha denominado 'didáctica' cuando realmente sus intereses fueron en su esencia semejantes a los que luego Montaigne denominaría Essais: una transmisión cultural de reelaboración personal, utilizando determinada perspectiva o punto de arranque como ocasión de un discurso más o menos libre o liberador. [...] Sin duda el proceso no culminó hasta M. de Montaigne de una manera consciente, pero este autor no hizo más que recoger elevándolas a la categoría de género las experiencias de una literatura renacentista que había tenido su máximo desarrollo en España: un abanico de tentativas ofrecían sin duda todos los rasgos por los que se ha definido el ensayo» (La prosa didáctica en el siglo XVI, op. Cit., págs. 11, 17).

7 José Lara Garrido, «Los Diálogos de la Montería de Luis Barahona de Soto como realización genérica», en Analecta Malacitana, II/1, 1979, págs. 49-69; «Los Diálogos de la Montería de Barahona de Soto: desestructuración expositiva y coherencia compendial», en Boletín de la Biblioteca de Menéndez Pelayo, LVIII, 1982, págs. 115-153.

8 Marie-Sol Ortola, Un estudio del «Viaje de Turquía». Autobiografía o ficción, Londres, Tamesis Books, 1983.

9 Leonardo Romero Tobar, «Antonio de Torquemada, el humanista vulgar de los Colloquios satíricos», en AA.VV., Estudios sobre el Siglo de Oro. Homenaje al profesor Francisco Ynduráin, Madrid, Editora Nacional, 1984, págs. 395-409; «El arte del diálogo en los Colloquios satíricos de Torquemada», en Edad de Oro, III, 1984, págs. 241-256. 
Rafael Malpartida Tirado

de Valdés ${ }^{10}$, por citar varias de las mejores muestras del género y sus respectivos exégetas, que han abordado de manera consustancial a su interpretación literaria los elementos inherentes al diálogo con los que se configuran.

El caso de la Honra de escribanos (1565) de Pedro de Madariaga resulta extremo, porque su filiación genérica ni siquiera se ha señalado en los escasos trabajos donde se menciona. De no ser por su presencia en los catálogos de diálogos renacentistas ${ }^{11}$, su condición dialogal habría permanecido totalmente inadvertida, ya que de esta obra, cuyas dos primeras partes son dialógicas, no se especifica su condición genérica ni en los diccionarios de calígrafos ${ }^{12} \mathrm{ni}$ en el artículo monográfico que Abraham Esteve Serrano le dedicó, donde no llega a señalar nunca que se trata de un diálogo, ni siquiera cuando reseña el contenido de esas dos primeras partes, limitándose a indicar que «constituyen un tratado de caligrafía» ${ }^{13}$.

No sólo el empleo del diálogo por parte de Madariaga, sino la incorporación de sus segmentos a una unidad mayor, merece cierta atención. Las peculiaridades de obras como el Diálogo de la lengua de Juan de Valdés, cuya excesiva distensión y complejidad de caracteres ${ }^{14}$ hacen dudar de su carácter catequístico, aunque formalmente la adscripción es clara, o los Diálogos de la montería de Barahona de Soto, donde las reticencias de uno de los interlocutores para ingresar en el ámbito doctrinal lindan con el diálogo polémico, dificultan su ingreso en la categorización matriz que hemos acogido. El ejemplo de la Honra de escribanos, sin embargo, no ofrece estos problemas, puesto que se divide en varios segmentos dialogales, cada uno de los cuales responde a una

10 Asunción Rallo, El «Mercurio y Carón» de Alfonso de Valdés. Construcción y sentido de un diálogo renacentista, Roma, Bulzoni, 1989.

11 Jacqueline Ferreras, Los diálogos humanísticos..., op. cit., pág. 35; Jesús Gómez, El diálogo en el Renacimiento español, Madrid, Cátedra, 1989, pág. 223.

12 Su condición dialogal pasa desapercibida, por ejemplo, para Manuel Rico y Sinobas (Diccionario de calígrafos españoles, Madrid, Real Academia Española, 1903, s. v. Madariaga, pág. 243). En el diccionario de Emilio Cotarelo y Mori se habla al menos de «diálogo» para localizar sus distintas partes en la descripción de la obra (Diccionario bibliográfico y biográfico de calígrafos españoles, Madrid, 1913-1916, s. v. Madariaga, vol. 2, págs. 6-12). A esta última obra remito para datos biográficos del autor, que de todas formas se han ido espigando de la propia obra, ante la escasez de documentación adicional.

13 Abraham Esteve Serrano, «El Libro subtilíssimo intitulado honra de escrivanos de Pedro de Madariaga», en AA. VV., Homenaje al Profesor Muñoz Cortés, Murcia, Universidad, 1976-1977, págs. 151-163, la cita en pág. 151.

14 Isaías Lerner ha explicado esta dinámica, aparentemente ajena a la construcción de un diálogo catequístico, mediante formulaciones oximorónicas como «amistosa agresividad» en cuanto a las relaciones entre los platicantes y «elaborada espontaneidad» en cuanto al estilo («El discurso literario del Diálogo de la lengua de Juan de Valdés», en A. David Kossoff et al. [eds.], Actas del VIII Congreso de la Asociación Internacional de Hispanistas. II, Madrid, Istmo, 1986, págs. 145-150). 
intencionalidad docente o a un fin polemista, con sus respectivas consecuencias formales, dependiendo de la función que le corresponde en relación a la estructura global de la obra. Esta se halla dividida en tres partes: siete diálogos donde diferentes interlocutores, asumiendo a veces una pertenencia geográfica que determina sus posiciones y los agrupa en varios bandos, entablan un duelo verbal sobre la facultad de la escritura; cinco diálogos que constituyen la parte central de la obra y la que se ha anunciado como gran novedad, donde se enseña el arte caligráfico por la vía catequística, salvo en el primero de ellos, claramente polémico; y por último un arte de ortografía presentado monológicamente.

La elección de esta diversidad de cauces resulta perfectamente acorde con los propósitos del autor, que se desentiende de cualquier criterio unificador - como el que acarreaba a Torquemada numerosas dificultades estructurales en su Manual de escribientes, diálogo que se desarrolla en una sola sesión- ${ }^{15} \mathrm{y}$ presenta su sistema caligráfico como discípulo de Juan de Yciar ${ }^{16}$ y con el refrendo de «más de quinientos discípulos», a pesar de las críticas «de los enemigos del provecho común» («Prólogo», s. n.) ${ }^{17}$.

Para la instauración de su método basado en el triángulo, Madariaga se ve en la necesidad de realizar inicialmente una apología del arte de la escritura, de manera que la primera parte de su obra se compone de una serie de diálogos polémicos donde se intenta demostrar en principio «la necessidad que todos los hombres tienen de saber escrivir, y cómo la pluma es instrumento del entendimiento humano» (fol. 1). Con este objetivo, encontramos en el diálogo primero a Gamboa y Manrique, dos caballeros caracterizados de entrada únicamente por su procedencia geográfica, vizcaíno el uno y castellano el otro. El resorte para que se encauce la plática, tras el encuentro fortuito en un espacio urbano, consiste en un discurso sobre la facultad de la escritura que ha escuchado el primero de ellos, tan sabroso y - por añadidura - avergonzador

\footnotetext{
15 De esas dificultades estructurales, que dejan huella en la recreación conversacional, trato en «El sueño de la imprenta engendra monstruos: la búsqueda de un nuevo lector en el Manual de escribientes de Antonio de Torquemada», en Juan Matas Caballero y José Manuel Trabado Cabado (eds.), Antonio de Torquemada y la Literatura del Siglo de Oro (en prensa).

16 De la doctrina de Madariaga da cuenta Daniel Alonso García para explicar la acogida y proyección histórica de las ideas caligráficas de su maestro Juan de Ycíar. Nótese que en su monográfico confunde la Honra de escribanos con una segunda edición de título diferente, Arte de escribir, ortografía de la pluma y honra de los profesores de este magisterio, publicada en Madrid, Antonio de Sancha, 1777, a la que asigna erróneamente la fecha de 1565 (Ioannes de Yciar, calígrafo durangués del siglo XVI. 1550-1950, Bilbao, Publicaciones de la Junta de Cultura de Vizcaya, 1953, págs. 88-90).

17 Todas las citas correspondientes a esta obra proceden de la siguiente edición: Pedro de Madariaga, Libro subtilissímo intitulado Honra de escrivanos, Valencia, Juan de Mey, 1565. En adelante me limito a indicar el número de folio.
} 
Rafael Malpartida Tirado

que le lleva a mascullar: «Jesu Christo nos guarde de toda ignorancia y error de entendimiento» (fol. 1), todo un estímulo para que Manrique se interese por el contenido de dicho discurso. Si este procedimiento puede emparentarse con el empleado por Juan de Valdés en su Alfabeto cristiano, pues se trata de los efectos que provocan las palabras de otro en uno de los interlocutores como motivo incitador de la conversación ${ }^{18}$, el referente básico de Madariaga está mucho más cerca temática y localmente, ya que en el simpático diálogo Scriptio de Juan Luis Vives, también sobre el arte caligráfico y desarrollado en el ámbito valenciano, hallamos un inicio muy semejante, con homonimia de uno de los dialogantes incluida:

MANRIQUE: ¿Estuviste hoy cuando aquel hombre hizo un discurso sobre la utilidad de la escritura?

MENDOZA: ¿En dónde?

MANRIQUE: En la clase de Antonio de Nebrija.

MENDOZA: En verdad no estuve. Pero tú pasa revista y mira a ver si recuerdas alguna cosa.

MANRIQUE: ¿De qué quieres que pase revista? Dijo tantas cosas, que casi todas se me han olvidado.

MENDOZA: Te ha pasado lo que dice Quintiliano que pasa con los recipientes de boca estrecha: escupen el líquido que se les vierte por encima en exceso; en cambio, si se lo echas con cuidado, lo engulle. ¿Pero no recuerdas nada en absoluto?

MANRIQUE: Casi nada.

MENDOZA: Pues algo es.

MANRIQUE: Pero muy poquito.

MENDOZA: Hazme también partícipe de ese poquito que dices ${ }^{19}$.

La reminiscencia de Vives en la práctica dialogal de Madariaga es evidente como punto de arranque; a partir de ahí, el prurito pedagógico que caracteriza a los Linguae latinae exercitatio, según el cual uno de los jóvenes, más

\footnotetext{
18 Las posibilidades pueden multiplicarse desde el discurso edificante que siembra dudas en la Julia Gonzaga del Alfabeto Cristiano, solventadas por el interlocutor Valdés, hasta la rememoración de una plática pretérita, recurso que tiene conocidos antecedentes clásicos; de hecho dos de los grandes modelos del género lo emplearon: Platón para recordar a Sócrates, y Cicerón asegurando que ha transcrito una conversación del pasado en De amicitia, por ejemplo.

19 Juan Luis Vives, Diálogos y otros escritos (introducción, traducción y notas de Juan Francisco Alcina), Barcelona, Planeta, 1988, pág. 41. El recurso se emplea también, por ejemplo, en la Ingeniosa comparación entre lo antiguo y lo presente (1539) de Villalón, donde Gaspar solicita a Hierónimo que le refiera una plática a la que él no pudo asistir, lo cual provoca en este caso la consecuente alusión a problemas mnemotécnicos: «no sé si me acordaré por orden todo lo que se trató, porque era más de las doze horas quando anoche nos fuymos a dormir, por ser tan larga la cuestión» (ed. de M. Serrano y Sanz, Madrid, Sociedad de Bibliófilos Españoles, 1898, pág. 135).
} 
avezado que el otro, lo anima a instruirse, es sustituido en la Honra de escribanos por un ejercicio mnemotécnico asociado a una función lúdica («afilar un poco su ingenio»). Se pone así de manifiesto la necesidad de completar con elementos de cosecha propia aquello que no se recuerda del discurso pretérito ${ }^{20}$ :

MANRIQUE 21 : Por cierto que me holgara de estar en essa plática, y si no fiasse de vuestra memoria, que me relataréys todo quanto ha dicho, no me aconortaría [...]

GAMBOA: ¡Bueno es esso! ¿Vuestra Merced quiere sacar burla de mi memoria? Si yo la tuviera tan buena como el rey Ciro, que nombrava y conoscía a todos sus soldados, que serían más de treynta mil, no fuera mucho acordarme punto por punto de todo.

MANRIQUE: No lo eche por aý, señor Gamboa, por escusarse del trabajo, que ya conoscéys que lo digo con affición, y aun yo conozco también que si en algo no os acordaseys de lo que el otro dijo, valdrá tanto y más lo que V. M. porná de su casa, si quiere afilar un poco su ingenio.

GAMBOA: Beso las manos a V. M. por el favor. Esso es por obligarme más a mí, y pues tanto lo desseáys, yo lo diré, pero con condición que si en algo echare avieso del camino ordinario y del parescer del vulgo, no os avéys de maravillar, pues soys discreto y entendido, porque tengo de tratar cosas nuevas y al parescer impossibles, mas muy importantes y provechosas, y tales que jamás por ventura $V$. M. oyó ni leyó. Y pues me days licencia que ponga también de mi casa, yo porné poco, pero procuraré que V. M. no vaya descontento de la plática, si está atento (fols. $1 \mathrm{v}^{\mathrm{o}}-2$ ).

Lo que se inicia bajo algunos presupuestos frecuentes en el diálogo catequístico, como el anhelo instructivo y la petición de datos a cargo del desinformado, en tanto que el informante alude a la dificultad de encauzar la

20 El gran referente de este recurso en el diálogo es Platón, pero no tanto como juego o adiestramiento del ingenio - que también están presentes en su obra, aunque de otro modo-, sino como procedimiento que hace ver al lector la dificultad de acceder al conocimiento (cf. Emilio Lledó, La memoria del Logos, Madrid, Taurus, 1984, págs. 56-58) y, en última instancia, dentro del rescate apologético de la figura de Sócrates, cuya intrincada reconstrucción mediante engastes narrativos contribuye a realzarla, de manera semejante a la conformación de otros personajes legendarios de los que no se conoce sino una sesgada información y procedente de diversas fuentes ( $c f$. ., por ejemplo, el inicio de El Banquete y de Fedón). Jean Andrieu ha explicado que «l'insérende représente un moyen à la fois discret et efficace de recréer la profondeur du passé» (Le dialogue antique. Structure et présentation, París, Les Belles Lettres, 1954, pág. 318).

21 Son tantas las coincidencias con el diálogo de Vives, especialmente en cuanto a técnica de construcción dialogal - la temática es también patente-, que se han deslizado incluso al terreno de lo anecdótico: probablemente por descuido, la abreviatura del nombre aparece aquí no como M., Ma. o Man., que son las más habituales en la obra, sino, curiosamente, como Me., abreviatura de Mendoza, el otro interlocutor de Scriptio. Parece haber traicionado aquí a Madariaga la discrepancia entre mente y pluma de la que se hablará más adelante en la Honra de escribanos. 
Rafael Malpartida Tirado

materia y termina aceptando con encarecimiento de la misma y solicitud de atención ${ }^{22}$, termina contaminándose con una tímida y esporádica pugna a la que Manrique alude tempranamente: «Pues comience V. M. si manda, que si una vez entramos en la disputa, no le dexaré salir tan presto della» (fol. $\left.2 \mathrm{v}^{\circ}\right)$. Acepta Gamboa delegando a veces la responsabilidad en el autor del discurso al que asistió: «[...] yo relataré solamente con brevedad lo que el otro dixo, aunque no sea sino por que Vuestra Merced me contradiga» (fol. $4 \mathrm{v}^{0}$ ). Por más que aflore en ciertas ocasiones el léxico argumentativo («si yo os provasse», fol. 4; «si tal cosa me persuadís», ibíd.; «esso os queda aún por provar», fol. 6), la conversación discurre de manera no muy alejada del modelo catequístico por cuanto predominan las preguntas ingenuas de Manrique y no ha de esforzarse demasiado Gamboa para convencer a su interlocutor de que «es la pluma tan acertado y eminente instrumento del entendimiento humano» (fol. 6).

En el diálogo segundo, que se desarrolla ese mismo día después de la comida, parece que la polémica va a animarse, ya que irrumpen dos nuevos interlocutores, Óñez y Lara. También caracterizados por su procedencia geográfica - ambos son vizcaínos, pero de familias enfrentadas - , cada uno de ellos asume una posición contraria y se suma a la disputa entablada esa mañana, el primero en ayuda de Gamboa y el segundo tomando la iniciativa a la hora de objetar, ya que Manrique se declara «medio vencido» (fol. 8) en la plática precedente y prefiere retirarse como mero testigo. La aportación de Lara, presentado como "gran argumentador», permite que el enfrentamiento verbal sea más encarnizado, poniéndose en juego un mayor número de referencias eruditas y anécdotas con valor probatorio. Concluye Gamboa que «el entendimiento se conserva por la pluma» y «queda, pues, el hombre que no tiene pluma sin sciencia ni prudencia para elegir lo bueno y desechar lo malo» (fol. 12), hasta el punto de que, como ya había apuntado en el anterior diálogo, un hombre que no domina la caligrafía es equiparable a las bestias, parentesco entre el entendimiento y la mano - que maneja la pluma - corroborado por autoridades como Salomón.

\footnotetext{
22 Estas constantes se aprecian en un ejemplo afín, el Manual de escribientes de Torquemada: «JOSEP: [...] yo tengo grandísimo deseo de saber escrevir y açertar a hazer una carta»; "ANTONIO: Cosa muy dificultosa y trauajosa es la que me pedís»; «ANTONIO: [...] lo que me pedís, avnque a vosotros os pareçe poco, es meterme en vn piélago sin hondo, y en vn lauorinto tan yntrincado y rebuelto que apenas se le halla entrada ni salida» (ed. de $\mathrm{M}^{\mathrm{a}}$. J. Canellada y A. Zamora, Madrid, Anejos del BRAE, 1970, págs. 67, 122 y 170). Estas dificultades a las que se enfrenta el maestro - las cuales, salvadas en última instancia, encarecen el propio diálogo-, son patentes en obras como el Diálogo de la lengua de Juan de Valdés, donde el improvisado docente protesta a menudo por la desaforada petición de sus amigos, a los que dice «Muy larga me la levantáis» (ed. de C. Barbolani, Madrid, Cátedra, 1998, págs. 131 y 144).
} 
En el tercer diálogo, que ofrece una línea de continuidad temporal y repite interlocutores, de modo que el criterio de segmentación es ahora argumental, se desentiende de cualquier mecanismo de homogeneidad estructural e incluso de los mínimos recursos de recreación conversacional, ya que los diálogos se cierran e inauguran abruptamente. Aquí se va más allá en la apología del oficio, pues el epígrafe asegura «que prueva cómo la pluma alcança más que el entendimiento humano y cómo es instrumento para paz y para vida» (fol. 14). Una vez admitido por parte de los oponentes que «agora no me paresce que tenemos que arguyr V. M. y yo contra estos señores, que ellos han provado bien su intención que la pluma es parte principal para el entendimiento» (ibíd.), Óñez indica que «aún me quedava lo mejor, porque han de saber que levanta mayor buelo la pluma que el entendimiento natural, y es de mayor dignidad y grandeza» (fol. $14 \mathrm{v}^{\circ}$ ). A la disputa, que incorpora de entrada vocabulario bélico cuyo sentido metafórico ha de aclararse cortésmente («MANRIQUE: [...] el señor Óñez enristra más la lança contra nosotros [...] / GAMBOA: [...] no se pelea aquí con lanças, sino con razones y autoridades», ibíd.), se añaden los argumentos de que la pluma también sirvió para registrar la fe en las Sagradas Escrituras y - apunta Gamboa - el propio Jesús «de su dedo sacratíssimo, con que crió a todo el hombre, cielos y tierra, hizo pluma, escriviendo en tierra, para restituyr en paz y dar vida a la adúltera accusada», lo cual arranca la entusiasta exclamación de Óñez $-\mathrm{y}$ puede que también la hilaridad del receptor moderno - : $« \mathrm{i}$, grande honra del escrivano, que el mismo dedo de Christo aya servido de pluma!» (fol. $17 \mathrm{v}^{\mathrm{o}}$ ). El lector familiarizado con los recursos argumentativos más frecuentes empleados en textos de la época, no se extrañará si la mera concatenación de retazos bíblicos y la recurrencia a la auctoritas más huera termina no sólo convenciendo a los oponentes, sino embobeciéndolos de tal modo que hasta el inicialmente fiero Lara interviene no ya como gran argumentador, sino como dócil oyente maravillado ante el discurso del bando contrario, y ruega que continúen mostrándole datos que le eran desconocidos: « ¿Cómo es esso? Contánoslo, que dezís tantas cosas nuevas y tan bien fundadas, que ya no estoy puesto sino en creeros» (fol. $\left.18 \mathrm{v}^{\mathrm{o}}\right)$; acabando él mismo en elogio de la escritura con una referencia semejante a las anteriores: «Y tanto más se entenderá el beneficio de la pluma que aun las sanctas ánimas de Purgatorio reciben refrigerio siempre que se haze mención de tan alegre escritura y tan solemne plumada» (fol. 19) ${ }^{23}$.

${ }^{23}$ La escasa resistencia de uno de los contendientes presenta diversos grados y funciones en el diálogo polémico: el diseño deficiente de la controversia, de entrada poco atrayente por los nombres parlantes de los interlocutores, que no permiten sorpresa alguna (Philolathes y Philodoxo), en el Diálogo en laude de las mujeres de Juan de Espinosa; la tendencia a lo informativo, tras la inicial polémica, en el quinto de los Coloquios satíricos de Antonio de Torquemada; o el paulatino y bien justificado convencimiento del Arcediano en el Diálogo de las cosas ocurridas en 
El cuarto diálogo presenta diferentes interlocutores, pero se relaciona con los anteriores porque sus conversantes parecen haber entreoído o al menos tener noticia de esos coloquios sobre la necesidad y preeminencia de la pluma, lamentándose uno de ellos, Estacio, por no haber podido inmiscuirse en estos: « ¿Cómo quisiera hallarme en la plática que han tenido aquellos cavalleros, que dizque defienden cómo la pluma es instrumento de la memoria!» (fol. $19 \mathrm{v}^{\mathrm{o}}$ ). Replica Balçola que ellos pueden remedar la conversación asumiendo sus respectivos pareceres, y pactan que este último y Sepúlveda defenderán el arte caligráfico, en tanto que Estacio y Monteros representarán la posición contraria. De acuerdo con el epígrafe, según el cual el diálogo «enseña cómo la pluma es principal instrumento de la memoria» (fol. 19), el reparto de funciones entre los interlocutores, que reproduce la antítesis propia del diálogo polémico, no es más que la excusa inicial para que se insista en que la pluma es madre de la sabiduría, pues la registra y evita los fallos de la memoria, limitada e insegura. Hay una particularidad: Monteros es mercader y se aprovecha esta circunstancia para propugnar que tanto estos como los notarios necesitan aprender el oficio para evitar que otros puedan escamotear sus negocios, como se hace ver mediante una sabrosa anécdota, la más interesante y mejor construida de toda la obra, donde una viuda perdió toda una fortuna por culpa de la impericia caligráfica de su esposo.

En contraste con el anterior «enseña», en el epígrafe del quinto diálogo, con nuevo cambio de interlocutores, se emplea el término "prueba», y efectivamente la polémica adquiere mayor relieve y se emplea una argumentación más sólida que la meramente basada en la auctoritas, ya que el objetivo es más alto: demostrar "cómo la pluma es una de las artes liberales, y aun tiene mayor grado que las otras y es propio exercicio de cavalleros» (fol. 25 $\mathrm{v}^{\mathrm{o}}$ ), asunto este último que es el motivo de arranque del diálogo con nuevo recuerdo del Scriptio de Vives en clave humorística:

URQUIÇU: ¡O, qué ruin letra haze V. M., señor Bernardo! ¿Hanle escarvado esse papel algunas gallinas?

YBARRA: ¿Y essa letra imbiáys a la Corte? Bien podrá despachar primero un correo que avise allá de parte de quién va la carta, porque no conoscerán essa firma.

URQUIÇU: Antes es mejor que no la acierten a leer, porque esso les bastará por escusa para no hazer lo que se pide por ella.

BERNARDO: Yo siempre escrivo por secretario, sino que este negocio no se puede encomendar a tercera persona.

Roma de Alfonso de Valdés, igual que sucede, no con fin político, sino con el objeto de instruir sobre materia cinegética, en los Diálogos de la montería de Luis Barahona de Soto para la aceptación de esta disciplina por parte de Solino. 
YBARRA: Desde agora, señor, que la podéys imbiar abierta, que bien secreta yrá, porque no havrá quien adevine essos garavatos, quanto más leerlos.

VIVES: Como los cavalleros tenemos por honra escrivir mal, por esso el señor Bernardo no es affectado (fol. 26) ${ }^{24}$.

Si Urquiçu defiende, encadenando anécdotas y citas eruditas, que la pluma debe figurar entre las siete artes liberales, Ybarra va más allá incluyéndola «entre las supremas facultades y sciencias inspiradas allá junto a la sancta Teología» 25 , pues no fue inventada por el hombre, como prueban distintas autoridades, hasta el punto de que Job, en la Biblia, «está llamando escrivano al mismo Dios» (fol. 29). Estos argumentos convencen a Vives, para quien «la pluma no sólo es generosa, mas aun es sancta y necessaria, y propriamente exercicio de cavalleros» (fol. 30), y finalmente a Bernardo, el cual termina admitiendo «que el escrivir es más que arte liberal, y que quanto más cavalleros, tenemos más necessidad de saber escrivir» (fol. 31), tras oír una anécdota referida por Urquiçu en la que un caballero cae en desgracia por no saber escribir.

El término clave del epígrafe con el que se presenta el sexto diálogo es diferente a los anteriores: «se cuenta cómo los sabios eran los mejores escrivanos, y los príncipes y grandes monarchas se preciaron de la pluma y la honraron, y quánto importa para el mercader la pluma ayuntada con el buen entendimiento» (ibíd.), pero también se adopta una disposición polémica, ya que Prudencio pide a Velgara y Petronia que le demuestren esa asociación entre caligrafía y sabiduría que habían entreoído en aquellas pláticas «del otro día, aý, al portal de Sanct Pablo» (fol. $31 \mathrm{v}^{\circ}$ ). De este modo, vuelve a enhebrarse un diálogo por remisión a otro de los que ya conocemos, como sucedía en el cuarto, y aquí también se pretende reproducir la pugna de la plática en la que no habían podido intervenir, sustituyendo los nuevos interlocutores a aquellos

24 Además del nombre de Vives elegido, que tendría que haber asignado a otro interlocutor si hubiera deseado redondear el homenaje, la broma de las gallinas está presente en Scriptio con idéntica función, subordinada a la idea antigua de que el noble tiene a gala no saber escribir bien: «MENDOZA: [...] el populacho de la nobleza valenciana no parece obedecer a esa regla. Se creen que lo bello y decoroso es no saber dibujar las letras. Piensan que son trazos de gallinas al escarbar, y que si no se les avisa antes qué mano lo ha escrito es cosa que no se puede adivinar» (Diálogos y otros escritos, op. cit., pág. 43).

${ }^{25}$ En su recorrido por este género de libros, Aurora Egido destaca de la Honra de escribanos que «sus pretensiones de aligerar el aprendizaje van unidas a toda una filosofía de lo que, en principio, era un mero oficio y él quiere elevar a la categoría de arte. En este sentido, la caligrafía, como la pintura, pretende convertir en artista al que trabaja de mero escribano, intentando también que la escritura, como tal ejercicio gráfico, se instale en el panteón de las artes liberales hasta acercarse a la misma teología» («Los manuales de escribientes desde el Siglo de Oro. Apuntes para la teoría de la escritura», en Bulletin Hispanique, 97/1, 1995, pág. 80). 
vizcaínos tan leídos cuya ausencia se lamenta como punto de partida. Las objeciones de Prudencio van siendo sorteadas por los apologistas de la escritura, que incorporan a su nómina de doctos hombres que atendieron a la caligrafía las figuras de Quintiliano, Vives - con mención explícita del diálogo Scriptio-, Erasmo y Mejía, pasando inmediatamente a ocuparse de un tema que ya había sido abordado en el diálogo cuarto, aquí ampliado con la aportación de nuevas anécdotas. A la pregunta más general que termina formulando Prudencio por mímesis de la conversación entre aquellos vizcaínos, «¿cómo la pluma puede honrar a nadie?» (fol. 35), claramente propuesta para justificar el título de la obra, contestan sus acompañantes encadenando una prolija relación de autoridades y aludiendo al célebre «Hablen cartas y callen barbas» que, como suele ser habitual, una vez tocado por la pluma cervantina ha generado bibliografía específica ${ }^{26}$.

En el séptimo y último diálogo de esta primera parte, preludiado por un epígrafe más breve que reza: «de las riquezas, del poder y provechos que trae la pluma» (fol. $37 \mathrm{v}^{\mathrm{o}}$ ), se repite un interlocutor del anterior, Petronia, que se encuentra con Sagunto e inicia una justificación histórica de los primores de la escritura. Irrumpe entonces un nuevo dialogante, Alegría, que trae un recado de Velgara: «El que començó esta plática dize que V. M. le dé la conclusión y brevemente se despida deste negocio» (fol. 40), responsabilidad que acepta gustoso, ahora secundado activamente por el recadero, llegando a señalar «que la pluma es un quinto elemento que sustenta y conserva el mundo todo» (fol. 41 $\mathrm{v}^{\mathrm{o}}$ ), y sobrepasa a otras disciplinas con creces porque

La Gramática no os vale sino en ciertos encerramientos, la Medicina no os da de comer hasta que se os caygan los dientes de viejo, la Oratoria os echa en un rincón si no tenéys acción natural, las Leyes os hazen dessear discordia entre vuestros vezinos, la Philosophía os mata de hambre; sola la sancta Theología con solos los medios para alcançarla es la que todos devríamos procurar, porque su gualardón no es en este suelo. Todo lo demás al fin os puede dexar; sola la pluma no os dexa, si guardáys los tres dedos de la derecha (ibíd.).

La segunda parte de la Honra de escribanos es «un arte para bien escrivir» cuyo cauce genérico idóneo es el diálogo catequístico, que permite reproducir las

\footnotetext{
${ }^{26}$ Cf. Antonio Castillo Gómez, «Hablen cartas y callen barbas», en Historiar, 4, 2000, págs. 116-127. En la obra de Madariaga se trata de subrayar la superioridad de la escritura sobre la oralidad, pues «la firma de un hombre tiene más crédito que sus palabras» (fols. $35 \mathrm{v}^{\circ}$-36). Debemos una hermosa consideración de la escritura a Pedro de Navarra: «DUQUE: [...] ¿Ay cosa ygual en el orbe que vn hombre hable y entienda a otro de Oriente a Poniente, y de Poniente al Setentrión, e que vno que a mil años que murió, hable cada día conmigo, e que yo, que biuo, pueda hablar desde aquí a dos mil años con los que vernán?» (Diálogos de la differencia del hablar al escrevir, Tolosa, Jacobo Colomerio, 1565?, fol. b 3).
} 
relaciones entre maestro y discípulos que el propio Madariaga había desarrollado en la ciudad de Valencia para introducir su método caligráfico. Ahora bien, el primero de los cinco nuevos diálogos es, como los anteriores, polémico, ya que el autor, tras haber dejado bien claro que la escritura no sólo es imprescindible, sino una de las grandes facultades del ser humano, ahora considera necesaria una propugna de la teorización frente a la mera práctica, de modo semejante a los preliminares del Manual de escribientes27.

El epígrafe de este primer diálogo es el siguiente: «se prueva cómo se enseña mejor y con más brevedad por arte que con solas materias ni por solo el uso vulgar» (fol. 43), y se inicia con una queja de Antígono, aprendiz de escribano que se ve incapaz de avanzar y es aconsejado por otro epígono, Florencio, que le demuestra la escasa utilidad de lo que se denomina «materias» y «cauletras», abogando por el aprendizaje teórico de la disciplina equilibrado con el ejercicio. La resistencia del desencantado alumno es en principio firme, pues objeta que Cicerón defendió la práctica y que conoce escribanos duchos en el oficio que todo lo aprendieron con el uso, a lo que replica Florencio que Cicerón recomendaba realmente un término medio entre arte y ejercicio, y que esos aventajados escribanos, si se hubieran preocupado también de conocer aspectos teóricos, habrían podido llegar a ser teólogos.

Para justificar la publicación del libro, se pone en boca de Florencio un razonamiento muy similar al empleado por Torquemada en los preliminares del Manual de escribientes: los antiguos aprendían por uso, confiados en la intuición, «como adevinando», sin orden ni fundamento, sometidos a la voluble opinión, en tanto que los modernos pueden incorporar el arte por su perspectiva cronológica privilegiada, avisados de errores pretéritos e iluminados por aciertos de los que les precedieron, a pesar de lo cual, concretando en el oficio de la pluma, constata el desorden imperante:

aunque ayuntéys quantos escrivanos hay, cada uno escrive de su manera, y assí no hallaréys conformidad entre ellos, más que entre médicos quando no aciertan la enfermedad, y aun muchas vezes veréys que un mismo maestro enseña a un discípulo de

\footnotetext{
27 En el diálogo de Torquemada, además de constituir la principal reclamación del autor en los preliminares, es uno de los resortes de la instrucción. La excesiva confianza de los discípulos en la propia práctica diaria o incluso en la capacidad innata para desempeñar el oficio de secretarios, les vale una reprimenda por no aplicarse al estudio y no «tener memoria de muchas cosas que me preguntáis, en las quales sería justo que estubiésedes ya tan enseñados que fuésedes mejores maestros que yo» (op. cit., pág. 65). En esta dialéctica entre ars y exercitatio, contrasta la opinión de Madariaga con la de su maestro Ycíar, que se contenta con señalar en el prólogo de su formulario epistolar que «el artificio no falta, aunque va secreto [...]; en esta compostura más se precia el [autor] de lo natural que del arte», y poco más podía decir teniendo en cuenta que su libro consiste en un simple repertorio de cartas que invita a imitar (Nuevo estillo de escrevir cartas mensageras sobre diversas materias, Zaragoza, Agostín Millán, 1552, fol. a 5).
} 
Rafael Malpartida Tirado

una manera y a otro de otra, y siendo la misma differencia de letra, y lo que peor es, a uno mismo hoy de una manera y mañana de otra. Mira si es confusión esta inconstancia tan grande (fols. $\left.45 \mathrm{v}^{\mathrm{o}}-46\right)$.

Surge así la Honra de escribanos para homogeneizar el método de enseñanza ${ }^{28}$ y acelerarlo de paso, asegurándose que en pocos meses se puede dominar el oficio si se atiende a un procedimiento determinado, que aún no se especifica pero en los diálogos posteriores se explicará con detalle. Lamenta al cabo Florencio, aprovechando todo lo que se dijo en la primera parte, aunque no interviniera en ella, que « ¿Tan poco pensáys que puede el entendimiento humano que para todas las otras sciencias haya inventado arte, y a esta que es instrumento de todas la dexe estar tan derramada y tan colgada de la fantasía de cada uno?» (fols. 47 v $\mathrm{v}^{\mathrm{o}}-48$ ), y Antígono claudica desechando su adhesión incondicional «a lo antiguo», ya que es lícito y conveniente, como le indica su interlocutor, «inventar alguna cosa mejor que los passados para el provecho común» (fol. 49).

Ese invento de Madariaga es explicado pormenorizadamente por un maestro, ayudado de Ginto, repetidor de la escuela, a dos alumnos que se presentan como caballeros, Ayala y Guevara, a lo largo de cuatro diálogos más en los que se traza un proceso de enseñanza gradual tras la delación de determinados errores comunes que cometen los discípulos y con el apoyo de numerosos dibujos. La impertinencia de Guevara a la hora de preguntar, frenada por Ginto, y el epígrafe del diálogo cuarto, «en que se prueva la necessidad del triángulo para escrivir, y cómo se ha de hazer» (fol. 58), no son óbice para considerar estos diálogos como catequísticos. El carácter díscolo de un alumno es compatible - y hasta eficaz a veces - con el método de preguntas y respuestas con objeto formativo, y la argumentación a favor de un método nuevo ante el que se muestran reacios los discentes representa un trámite necesario para que se ingrese firmemente en la interacción pedagógica, pero lo que impera es el cauce expositivo predominante en el modelo catequístico.

La tercera parte de la obra ya no es dialogada. Madariaga ha preferido la forma monológica y la estructuración en capítulos, treinta y seis en total, para

\footnotetext{
${ }_{28}$ Cometido semejante es el de Francisco Lucas, para quien «ninguna cosa auía tan contraria para aprender bien a escreuir como la muchedumbre de letras que se enseñauan [...]. Y assí sería cosa de grandíssimo prouecho que todos los que aprenden trabajassen por escreuir bien vna suerte de letra, porque sabida bien vna, tienen aparejo y disposición para todo lo que quisieren» (Arte de escrevir, Madrid, Alonso Gómez, 1577, s. n.). Aurora Egido ha asociado agudamente esta obra con las de Torquemada y Madariaga: «La escritura se concibe, para Madariaga, como camino de perfección personal y hasta social. Aspecto este último fundamental para entender los constantes intentos de ascensión que laten, desde Torquemada, en los manuales de escribientes, y que también aparecen en el Arte de escribir (1577) de Francisco Lucas» («Los manuales de escribientes...», loc. cit., págs. 80-81).
} 
ofrecer un tratado ortográfico que presenta como lo más importante del libro y como una aportación novedosa, ya que «ninguno antes de mí (que a mi noticia aya llegado) ha dado arte general y méthodo para escrevir verdadero» (fol. 75 $\left.\mathrm{v}^{0}\right)^{29}$. Lo curioso de esta parte, en la que acota materia ocupándose exclusivamente «de las diciones que traen dificultad» (fol. 76), y que remata con unas particularidades y loa de la lengua vizcaína, es que está integrada artificiosamente en el conjunto de la obra, ya que se menciona en la anterior parte y remite a su vez a otros segmentos, de manera que la voz monologal se equipara a la de los conversantes de los diálogos. Dos ejemplos de esta desvirtuación de la recreación conversacional: al final de la segunda parte, el maestro indica que «os aprovechará también trasladar muchas vezes la tercera parte deste libro por que os quede en la memoria» (fol. 74), y ya en el tratado ortográfico, donde se enumeran, sin explicación alguna por la última incorporación, «los nombres de las artes liberales y facultades principales: Dialéctica, Theología, Pluma», se da por supuesto que el lector ha aplaudido las tesis de la primera parte, y se alude al "primer abecedario que dimos en el triángulo», lo cual se explicaba en la segunda parte (fol. 77).

Madariaga ha incluido en sus coloquios lazos de convivencia y se ha valido parcialmente de la repetición de interlocutores, al modo de Pedro Mejía en sus Diálogos, así que se leen homogéneamente, pero dinamita la recreación conversacional porque queda al descubierto el artificio del género en menciones del tipo: «como está bien provado en el primero y segundo diálogo» (fol. 28), palabras de un interlocutor que no tiene relación con los mismos, además de que el término «diálogo» se emplea en el sentido de composición literaria y no como sinónimo de los más frecuentes «plática» y «conversación». A esta circunstancia, que rompe la ilusión de autenticidad, podríamos sumar asimismo el inicio y cierre abruptos de cada diálogo, sin fórmulas de saludo o despedida y ni siquiera con una intervención de síntesis o remate argumental. Al autor sólo le interesa la utilidad de la obra, y los cauces elegidos están subordinados exclusivamente al contenido, sin atención alguna a la recreación conversacional. El procedimiento de interrelacionar los diálogos en un marco urbano y como suma de réplicas de otras conversaciones entreoídas, se encamina a contagiar al lector de ese entusiasmo por la plática provechosa y el ejercicio dialéctico que derrochan algunos interlocutores lamentándose de no haber intervenido en sabrosas reuniones.

${ }^{29}$ Es esta sección la que le ha reportado mayor número de menciones entre los críticos modernos. Lo citan, por ejemplo, Rosario Russotto y Luis Álvarez, «El sistema ortográfico del español», en Revista de Filología de la Universidad de la Laguna, 13, 1994, pág. 343; y Ramón Santiago, "Apuntes para la historia de la puntuación en los siglos XVI y XVII», en J. M. Blecua, J. Gutiérrez y L. Sala (eds.), Estudios de grafemática en el dominio hispano, Salamanca, Universidad de Salamanca/Instituto Caro y Cuervo, 1998, pág. 253. 
Rafael Malpartida Tirado

Es preciso retomar en este punto el prólogo para extraer algunas conclusiones de la disposición estructural de la Honra de escribanos y la acogida de diferentes modalidades genéricas. Madariaga exacerba lo que podría denominarse, para el caso del Manual de escribientes de Torquemada, «polivalencia práctica», ya que no sólo propugna la necesidad de que todos aprendan el arte caligráfico y ofrece su método envuelto en una aureola de novedad y eficacia, sino que pretende vender los diálogos para que los maestros enseñen a leer a sus alumnos y como estímulo para el estudio y ejercicio oratorio ${ }^{30}$. Pero lo más interesante para nuestro cometido es la distinción que el autor realiza entre la segunda y tercera parte, que «enseñan», y la primera, que «enseña y aplaze» («Prólogo», s. n.), de manera que añade un componente recreativo a los diálogos polémicos, ausente de los catequísticos y del tratado ortográfico. A la confrontación, por débil que sea, como se ha señalado en la descripción de varios diálogos, se le asigna una función lúdica inseparable de la didáctica, y es que Madariaga desea atrapar al lector desde el inicio y, una vez defendida su postura teórica, presentarle lo más árido, que son indudablemente el sistema de escritura y la Ortografía. Por tanto, no es el diálogo para Madariaga, en términos generales, un endulzador doctrinal, sino más concretamente la modalidad polémica la que se asocia al delectare y prepara incluyéndolo también - el prodesse.

La segunda conclusión que se desprende consiste en que el diálogo polémico se emplea como recurso apologético (virtudes del arte caligráfico) y justificador metodológico (codificación y estabilidad teórica de la disciplina) que necesariamente han de preceder a la exposición del sistema que propone Madariaga.

He aquí un esquema de las diferentes modalidades dialógicas y su incorporación al entramado estructural de la obra:

\footnotetext{
30 Madariaga recomienda aplicaciones que no dejan de resultar pintorescas y que se asocian al modo de concebir el diálogo por parte del primer Erasmo y de Vives, con la particularidad de que ahora ya no se trata de enseñar latín, sino de que se practique el castellano, y aún hay más, pues el ámbito de difusión no se reduce al «puer», sino que se extiende incluso «a los mayorcillos». La advertencia revela que el género se concebía al servicio de la educación más elemental, y puramente lingüística, más a menudo de lo que puede pensarse: «En lo que toca a la primera parte, aviso a los maestros que enseñan a leer que quando los niños sepan leer unos siete psalmos, luego les den estos diálogos, si quieren sacar infinitos provechos de sus ingenios. Porque, lo primero, leerán más presto en lengua vulgar que en latín y se desembolverán a saber hablar entre hombres interrogando y respondiendo, sin aquella vergüença rústica, que es un provecho no conoscido, y aun para esto aprovechará también a los mayorcillos hazerles decorar y recitar ante mucha gente. Lo segundo, se afficionarán no sólo a escrivir, pero a la virtud y a todos los estudios. Lo tercero, les abrirá mucho el entendimiento y apercibirá sus ingenios para sus estudios y para qualquier negocio» («Prólogo», s. n.).
} 


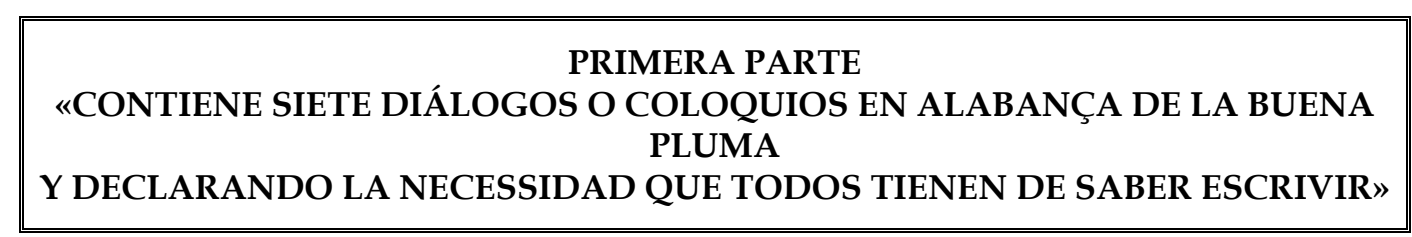

\begin{tabular}{|c|c|c|c|c|}
\hline $\begin{array}{c}\text { DIÁLOGO } \\
1^{\circ}\end{array}$ & POLÉMICO & GAMBOA & MANRIQUE & $\begin{array}{c}\text { «NECESSIDAD QUE } \\
\text { TODOS LOS HOMBRES } \\
\text { TIENEN DE ESCRIVIR» } \\
\text { «LA PLUMA ES } \\
\text { INSTRUMENTO DEL } \\
\text { ENTENDIMIENTO } \\
\text { HUMANO» }\end{array}$ \\
\hline $\begin{array}{c}\text { DIÁLOGO } \\
2^{\circ}\end{array}$ & POLÉMICO & $\begin{array}{l}\text { GAMBOA - } \\
\text { ÓÑEZ }\end{array}$ & $\begin{array}{l}\text { MANRIQUE - } \\
\text { LARA }\end{array}$ & $\begin{array}{c}\text { «LA PLUMA ES } \\
\text { INSTRUMENTO DEL } \\
\text { ENTENDIMIENTO } \\
\text { HUMANO» }\end{array}$ \\
\hline $\begin{array}{c}\text { DIÁLOGO } \\
3^{\circ}\end{array}$ & POLÉMICO & \multicolumn{2}{|c|}{ ÍDEM } & $\begin{array}{c}\text { «A PLUMA ALCANÇA } \\
\text { MÁS QUE EL } \\
\text { ENTENDIMIENTO } \\
\text { HUMANO» }\end{array}$ \\
\hline $\begin{array}{c}\text { DIÁLOGO } \\
4^{\circ}\end{array}$ & POLÉMICO & $\begin{array}{l}\text { BALÇOLA - } \\
\text { SEPÚLVEDA }\end{array}$ & $\begin{array}{c}\text { ESTACIO - } \\
\text { MONTEROS }\end{array}$ & $\begin{array}{c}\text { «LA PLUMA ES } \\
\text { PRINCIPAL } \\
\text { INSTRUMENTO DE LA } \\
\text { MEMORIA» }\end{array}$ \\
\hline $\begin{array}{c}\text { DIÁLOGO } \\
5^{\circ}\end{array}$ & POLÉMICO & $\begin{array}{l}\text { YBARRA - } \\
\text { URQUIÇU }\end{array}$ & $\begin{array}{l}\text { BERNARDO - } \\
\text { VIVES }\end{array}$ & $\begin{array}{c}\text { «LA PLUMA ES UNA DE } \\
\text { LAS ARTES LIBERALES, } \\
\text { Y AUN TIENE MAYOR } \\
\text { GRADO QUE LAS } \\
\text { OTRAS» } \\
\text { «ES PROPRIO EJERCICIO } \\
\text { DE CAVALLEROS» }\end{array}$ \\
\hline
\end{tabular}




\begin{tabular}{|c|c|c|c|c|}
\hline $\begin{array}{c}\text { DIÁLOGO } \\
6^{\circ}\end{array}$ & POLÉMICO & $\begin{array}{c}\text { PETRONIA - } \\
\text { VELGARA }\end{array}$ & PRUDENCIO & $\begin{array}{c}\text { «OS MÁS SABIOS ERAN } \\
\text { LOS MEJORES } \\
\text { ESCRIVANOS» } \\
\text { «LOS PRÍNCIPES Y } \\
\text { GRANDES MONARCAS } \\
\text { SE PRECIARON DE LA } \\
\text { PLUMA» } \\
\text { «QUÁNTO IMPORTA } \\
\text { PARA EL MERCADER } \\
\text { LA PLUMA AYUNTADA } \\
\text { CON EL BUEN } \\
\text { ENTENDIMIENTO» }\end{array}$ \\
\hline $\begin{array}{c}\text { DIÁLOGO } \\
7^{\circ}\end{array}$ & POLÉMICO & $\begin{array}{c}\text { PETRONIA - } \\
\text { ALEGRÍA }\end{array}$ & SAGUNTO & $\begin{array}{c}\text { «DE LAS RIQUEZAS, } \\
\text { DEL PODER Y } \\
\text { PROVECHOS QUE TRAE } \\
\text { LA PLUMA» }\end{array}$ \\
\hline
\end{tabular}

\section{SEGUNDA PARTE}

«LLEVA UNA ARTE BREVÍSSIMA POR LA QUAL CADA UNO PUEDE SALIR BUEN ESCRIVANO

EN MENOS DE DOS MESES SIN MATERIAS Y SIN MAESTRO»

\begin{tabular}{|c|c|c|c|c|}
\hline $\begin{array}{c}\text { DIÁLOGO } \\
1^{\circ}\end{array}$ & POLÉMICO & FLORENCIO & ANTÍGONO & $\begin{array}{c}\text { «SE ENSEÑA MEJOR } \\
\text { Y CON MÁS } \\
\text { BREVEDAD POR } \\
\text { ARTE QUE CON } \\
\text { SOLAS MATERIAS } \\
\text { NI POR SOLO EL } \\
\text { USO VULGAR» }\end{array}$ \\
\hline $\begin{array}{c}\text { DIÁLOGO } \\
2^{\circ}\end{array}$ & $\begin{array}{c}\text { CATEQUÍS - } \\
\text { TICO }\end{array}$ & $\begin{array}{l}\text { EL MAESTRO - } \\
\text { GINTO }\end{array}$ & $\begin{array}{l}\text { AYALA - } \\
\text { GUEVARA }\end{array}$ & $\begin{array}{c}\text { «SE DESECHAN } \\
\text { ALGUNOS ABUSOS» } \\
\text { «COMIENÇAN LOS } \\
\text { PRECEPTOS DEL } \\
\text { ARTE» }\end{array}$ \\
\hline $\begin{array}{c}\text { DIÁLOGO } \\
3^{\circ}\end{array}$ & $\begin{array}{c}\text { CATEQUÍS - } \\
\text { TICO }\end{array}$ & \multicolumn{2}{|c|}{ ÍDEM } & $\begin{array}{c}\text { «COMIENÇAN LOS } \\
\text { PRINCIPIOS DEL } \\
\text { ARTE» }\end{array}$ \\
\hline
\end{tabular}




\begin{tabular}{|c|c|c|c|}
\hline $\begin{array}{c}\text { DIÁLOGO } \\
4^{\circ}\end{array}$ & $\begin{array}{c}\text { CATEQUÍS - } \\
\text { TI CO }\end{array}$ & ÍDEM & $\begin{array}{l}\text { «SE PRUEVA LA } \\
\text { NECESSIDAD DEL } \\
\text { TRIÁNGULO PARA } \\
\text { ESCRIVIR Y CÓMO } \\
\text { SE HA DE HAZER» }\end{array}$ \\
\hline $\begin{array}{c}\text { DIÁLOGO } \\
5^{\circ}\end{array}$ & $\begin{array}{c}\text { CATEQUÍS - } \\
\text { TICO }\end{array}$ & ÍDEM & $\begin{array}{c}\text { «ENSEÑA CÓMO SE } \\
\text { SACAN TODAS LAS } \\
\text { LETRAS DEL } \\
\text { TRIÁNGULO» }\end{array}$ \\
\hline
\end{tabular}

TERCERA PARTE

«SE DA OTRA ARTE DE ORTHOGRAPHÍA PARA ESCRIVIR VERDADERO EN QUALQUIER LENGUAJE»

\begin{tabular}{|c||c||}
\hline FORMA & «SE DA ARTE PARA ESCREVIR Y PRONUNCIAR \\
MONOLÓGICA & VERDADERO, ASSÍ EN ROMANCE CASTELLANO Y EN \\
QUALQUIER LENGUA VULGAR, COMO EN LATÍN, POR \\
OTRO NOMBRE ORTHOGRAPHÍA»
\end{tabular}

El contenido heterogéneo que Torquemada vierte en su Manual de escribientes por considerar que son muchas las cualidades y conocimientos que debe atesorar el profesional al que dirige su obra, contribuye a dificultar su estructuración en un diálogo continuado ${ }^{31}$. Madariaga ha optado, en cambio, para difundir un contenido menos complejo y variado, por una solución más cómoda, ya que no es preciso justificar el tránsito de una materia a otra e incluso su repetición o amplificación, al tratarse de diálogos breves e independientes en su mayoría, cuya unidad depende de su integración en el libro. Esta no se oculta, como hemos observado, en ninguna de las partes, pues se deja al descubierto el artificio conversacional.

\footnotetext{
31 Antonio Prieto advierte que «más allá de su funcionalidad para secretarios, el Manual dialogado de Torquemada expresa una conducta epistolar renacentista que corre por predios literarios y un sentido de obra literaria, como diálogo, relacionable con sus Colloquios y su Jardín» (La prosa española en el siglo XVI, Madrid, Cátedra, 1986, pág. 247). Lina Rodríguez Cacho insiste en los más altos vuelos que el astorgano reclamaba para su oficio: "Que Torquemada equipara la formación del secretario a la del perfecto humanista es algo que se deduce fácilmente de las exigencias culturales que encabezan su Manual» («La frustración del humanista escribiente en el siglo XVI: el caso de Antonio de Torquemada», en Criticón, 44, 1988, pág. 66).
} 
Que en algunos casos se aluda a conversaciones pretéritas e incluso se remede la controversia de estas, no es sino un medio esporádicamente empleado para impulsar la plática, como si un tema de debate se hubiera puesto de moda en la plaza valenciana, comenzando a expandirse merced a la iniciativa de unos caballeros vizcaínos que rescatan la caligrafía del «rincón fuera de las artes liberales» en el que se hallaba, propiciando así la introducción de un nuevo método de enseñanza, que no es sino la historia profesional del autor convertida en libro.

Se vale así Madariaga de una serie de diálogos polémicos con fin apologético, como pórtico de los catequísticos, para justificar la sistematización de su método basado en el triángulo. No es de extrañar que la polémica sea casi siempre débil, lindando con el tipo catequístico, pues la capacidad de resistencia ideológica de los interlocutores que objetan es vencida fácilmente y sin que observemos un convencimiento gradual, algo característico del diálogo polémico cuando está subordinado al elogio de una profesión que comparte el autor. Tan convencido parece Madariaga de la gloria de su oficio que apenas si puede fingir réplicas medianamente sólidas para demostrar lo contrario y mantener candente la disputa. El hecho de que el autor confunda el soporte material del intelecto, la escritura, con el intelecto mismo, le permite ocasionalmente enhebrar un discurso argumentativo satisfactorio incluso para el lector actual, pero lo preponderante en la Honra de escribanos es la hipérbolica alabanza de la caligrafía mediante la concatenación de autoridades frecuente en la prosa retórica de la época, y es que difícilmente habría podido demostrar determinadas tesis si no es acudiendo al socorrido e incontestable magister dixit. 